\title{
The Problem of Testing the Grouting of Prestressing Reinforcement - Use of Radiography
}

\author{
O. Anton* \\ Brno University of Technology, Faculty of Civil Engineering, Brno, Czech Republic, \\ *Corresponding author: anton.o@fce.vutbr.cz
}

DOI: $10.2478 / v 10158-010-0002-4$

ABSTRACT: One of the less frequent requirements from real world condition is to verify the correctness of the grouting of prestressed reinforcement. The experiment described in this paper aims at examining the possibilities of Co-60 radiography in solving this problem, depending on the thickness of the concrete, the form of defect, and the space configuration of the radiography of this defect.

KEY WORDS: Radiography, prestressing cables.

\section{INTRODUCTION}

One of the tasks of standard practice is to verify the correctness of grouting of prestressing reinforcement. One of the few methods effective in this case is Co-60 radiography. The following experiment was supposed to examine the extent of the possibilities of this nondestructive method for various thicknesses of concrete and various forms of grouting defects. As this issue was only marginal in the extensive research in progress, the experiment was carried out for one shape alternative of prestressing reinforcement only.

\section{SAMPLES AND CHOICE OF RADIOGRAPHIC CONFIGURATIONS}

This experiment was carried out in connection with the previously performed tests related to the possibility of imaging and identification of steel reinforcement in concrete depending on the type of reinforcement, its diameter, depth of its placement, and on the thickness of irradiated concrete.

The Co-60 isotope placed in the TECH/OPS radiographic cover was used as the source of radiation. The Co-60 used for experiments had an activity of approx. 1TBq, and it is at the moment the highest activity isotope in the Czech Republic designated for the irradiation of structures.

On the basis of experience, we chose the most commonly used radiographic film with the D7 sensitivity, Testix C7 NEW NIF, which is probably the highest quality Agfa product. As regards the format, we chose the largest size available on the market at the moment, i.e. $400 \times 300 \mathrm{~mm}$. Solid film cassettes were equipped with a pair of lead intensifying foils, which made for a substantial shortening of exposures with a simultaneous minimum decrease in the quality of radiograms (the use of other than metal foils was 
not considered, precisely for preserving the highest possible quality of radiograms). The films were developed using a standard development process in the darkroom of the Radiation Defectoscopy Centre. The use of new chemicals was guaranteed in order to lower the possibility of results deformation due to an incorrect development process.

The evaluation of radiograms was carried out on a pair of negatoscopes varying in the luminous intensity, which eliminated the possibility of misinterpreting the results due to the use of an unsuitable luminous intensity of the device. The apparatuses used were: L 120 apparatus with a lower luminous intensity but with a larger viewport, and Andrex with a higher, adjustable luminous intensity, but with a smaller viewport. For measuring the blackening of radiograms we used a densitometer with calibration scales for blackening.

We used an irradiation path made of concrete slabs with the dimensions of $500 \times 400 \times 50 \mathrm{~mm}$ in order to simulate various thicknesses of concrete. The path was complemented with samples in the form of concrete beams with the dimensions of $100 \times 100 \times 400 \mathrm{~mm}$. In the centre of each beam, there was a plastic sleeve with a diameter of $50 \mathrm{~mm}$. In the sleeve there was a prestressing cable made up of 7 wires with a diameter of $5 \mathrm{~mm}$. The cable was then grouted in various ways and simulations of various grouting defects were made. The grouting was simulated by a compacted cement paste.

A total of five samples were created:

Sample 1 reinforcement fully grouted all along its length.

Sample 2 reinforcement grouted to a half of the length of the beam (duct).

Sample 3 reinforcement completely ungrouted all along its length.

Sample 4 reinforcement grouted longitudinally to a half of its length in the plane perpendicular (parallel) to the beam walls.

Sample 5 reinforcement grouted longitudinally to a half of its length in an inclined plane (grouting plane crosses the beam edges).

The last sample (beam labeled 0) was created as a comparative gauge with holes, where steel wires with diameters according to ČSN 731376 were embedded in concrete transversely. This meant embedding two groups of wires in concrete, the first one, with diameters of $1,2,3,4,5,6 \mathrm{~mm}$, and the second one, with diameters of $4,6,8,10,14,16$, $20 \mathrm{~mm}$. After the setting of the concrete, the wires were removed and the result was a sample with holes of precisely defined diameters.

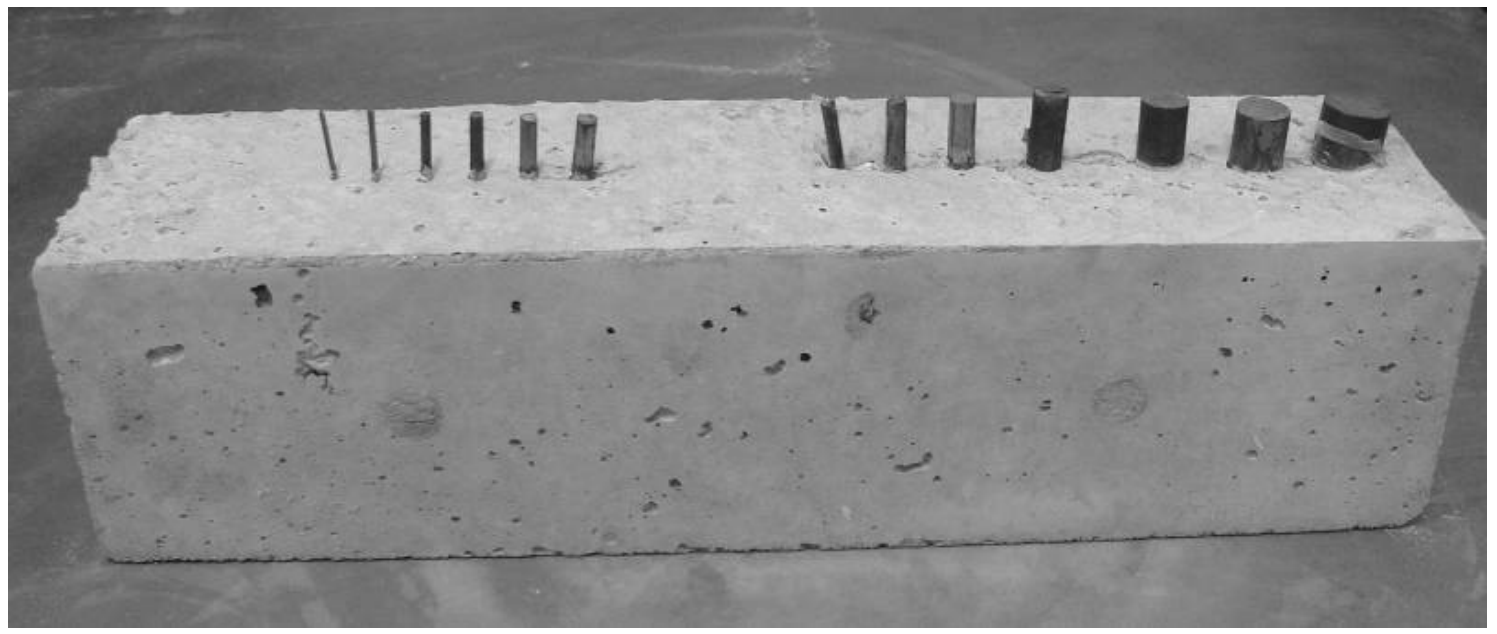

Figure1: Sample 0 before removing the wires defining the future holes. 


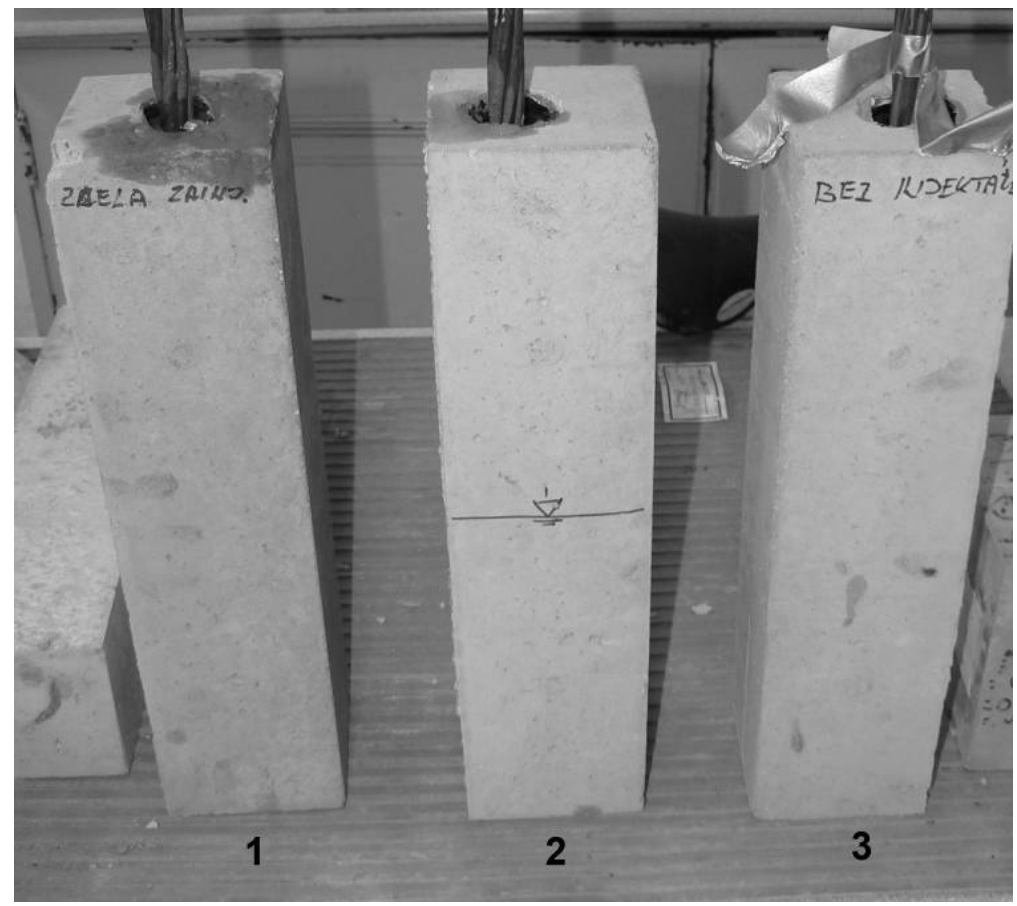

Figure2: Samples 1, 2 and 3 after the simulation of grouting.

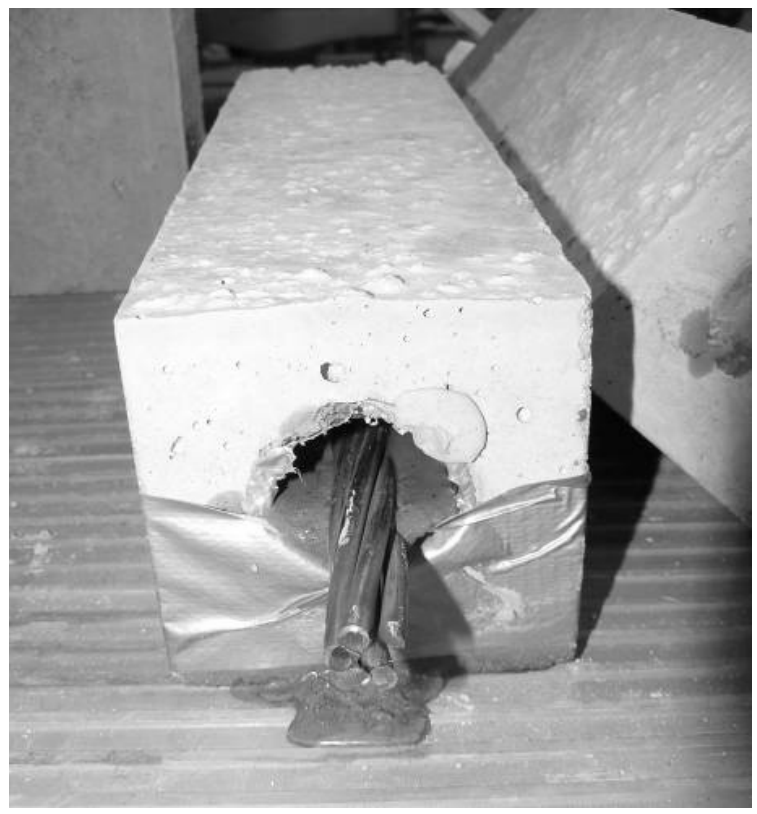

Figure3: Sample 4 after the simulation of grouting, on the right we can see a part of sample 5.

Considering the experiment results, we could assume (in analogy with the reinforcement of the circular section) that the position of reinforcement in the profile will not be decisive; the decisive factor for the differentiability will be the thickness of concrete. That is why the radiographic configurations were simplified so that it could be possible, considering 
the geometry, to always irradiate two samples at a time, i.e., samples were always placed as close as possible to the radiographic film.

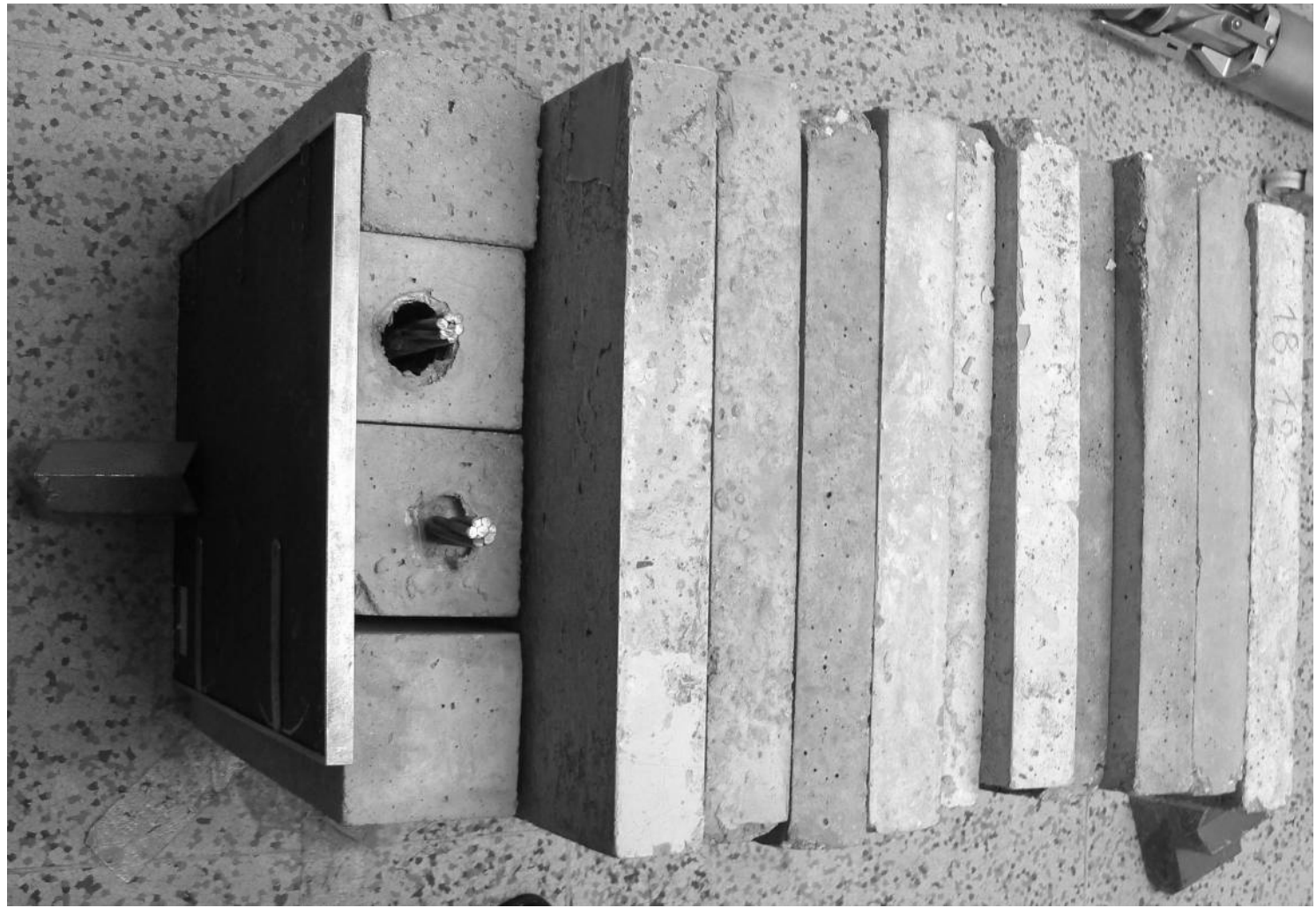

Figure4: Irradiation path during the radiography of configuration A - 6 .

The radiographic configurations were labeled with a transparent system of letters and numbers.

A - Samples 1 and 3 were irradiated

$\mathrm{B}$ - Samples 4 and 5 were irradiated

$\mathrm{C}$ - Samples 0 and 2 were irradiated

Number $(1,2,3,4,5,6)-1 / 100$ of concrete thickness in mm

In order to avoid doubts in the identification of radiograms, during each exposure the surface of the outside slab was provided with a lead mark corresponding to the configuration mark.

\section{FOCAL DISTANCE AND EXPOSURE TIME}

In view of a suitable geometry of irradiation, the basic focal distance chosen was $400 \mathrm{~mm}$. In the case of a greater thickness of concrete, the focal distance chosen equaled the thickness of concrete. With this focal distance we can still achieve acceptable exposure times. On the basis of the previous experiments, in places where radiation passed through the full concrete in all its thickness, the density of blackening chosen was about $\mathrm{D}=3,0$. 
6 thicknesses of concrete were chosen for the experiment, from 100 to $600 \mathrm{~mm}$ (600 mm was taken as a boundary thickness for Co-60 irradiation).

Table 1: Proposed exposures and testing blackenings estimated.

\begin{tabular}{|c|c|c|c|}
\hline $\begin{array}{c}\text { Thickness of } \\
\text { concrete }(\mathrm{mm})\end{array}$ & Focal distance $(\mathrm{mm})$ & Exposure time (min) & $\begin{array}{c}\text { Highest blackening } \\
\text { estimated D }\end{array}$ \\
\hline 100 & 400 & 2.6 & 3.0 \\
\hline 200 & 400 & 5.9 & 3.0 \\
\hline 300 & 400 & 13.4 & 3.0 \\
\hline 400 & 400 & 33.5 & 3.0 \\
\hline 500 & 500 & 118.0 & 3.0 \\
\hline 600 & 600 & 388.0 & 3.0 \\
\hline
\end{tabular}

\section{GAUGES AND DISCERNABILITY OF THE IMAGE OF HOLES}

In the experiment we used an alternative gauge described above in the form of holes made in the beam. Positioning the gauge on the side of the irradiator, as described by the standard, was not possible due to the geometry of irradiation and high thickness of concrete.

It was found during the experiment that the group of holes with smaller diameters is, in fact, unusable; the group of holes with diameters $4-20 \mathrm{~mm}$ is sufficient.

An experiment was carried out to evaluate the discernibility of the radiogram according to ČSN 731376 by the imaging of holes (a hole with the smallest diameter that is still visible is decisive).

Table 2: Evaluation of the discernibility of radiogram using the hole gauge according to ČSN 731376.

\begin{tabular}{|c|c|c|}
\hline Thickness (mm) & $\begin{array}{c}\text { Smallest diameter of the hole } \\
\text { Dmin } \\
\text { (gauge next to the film) }\end{array}$ & $\begin{array}{c}\text { Discernibility of the radiogram } \\
\text { Y } \\
\text { (gauge next to the film) }\end{array}$ \\
\hline \hline 100 & 3 & 3 \\
\hline 200 & 6 & 3 \\
\hline 300 & 8 & 3.7 \\
\hline 400 & 14 & 3.2 \\
\hline 500 & 16 & 3.3 \\
\hline 600 & 20 & \begin{tabular}{c} 
( \\
\hline
\end{tabular} \\
\hline
\end{tabular}

In conclusion, it is possible to say that the discernibility of all images is in compliance with ČSN 731376 as an approximate imaging method. As an exact method, however, none of the radiograms are satisfactory. Nevertheless, in this respect, the standard does not specify in more detail what both these types of methods represent in the identification of holes, and this classification is therefore largely irrelevant. Moreover, there is no need to point out that using similar gauges in practice for radiography in the field would be almost impracticable. Using the mentioned standard for this application of radiography is therefore absolutely impossible.

Much more interesting, however, is the possibility to identify holes of various sizes depending on the irradiated thickness, as seen in the following graph. 


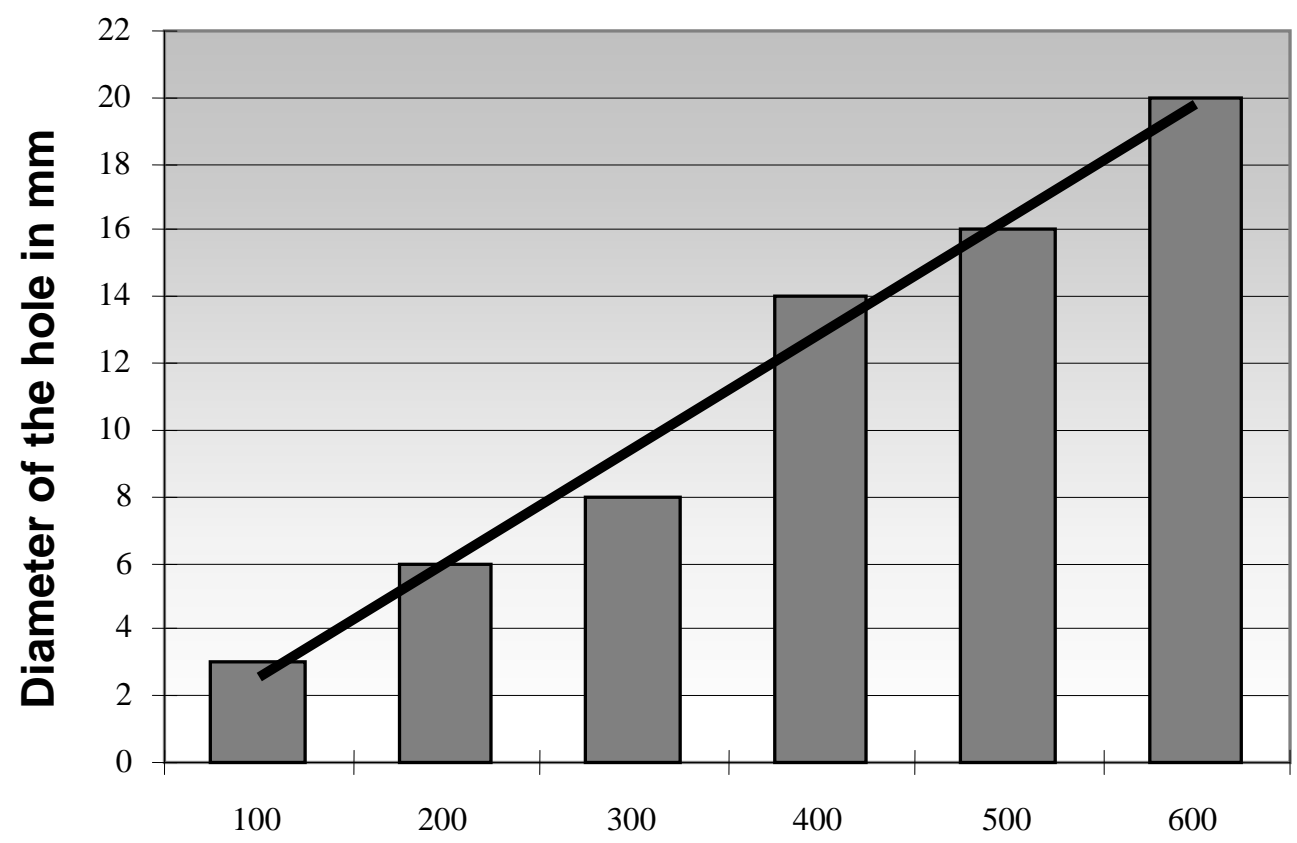

Thickness of concrete in $\mathrm{mm}$

Figure5: Possibility to identify holes according to their size and thickness of concrete.

\section{IDENTIFICATION OF PRESTRESSING REINFORCEMENT GROUTING DEFECTS}

All the created samples were gradually irradiated in such a manner to simulate the total thicknesses of concrete from 100 to $600 \mathrm{~mm}$. In all the radiograms, blackening was measured in the area of the grouted duct, the ungrouted duct, at the site of the displayed reinforcement, and immediately next to the duct.

All the radiograms, blackenings measured, and comments on radiograms can be found in Appendix 9.

\subsection{Sample 1 - reinforcement fully grouted}

Radiograms are characterized by an even blackening in the area of the sleeve of prestressing reinforcement. Blackenings at the site of the sleeve and outside it differ only very slightly (differences ranging from 0.01 to 0.04 ). It is possible to say that up to concrete thicknesses of $500 \mathrm{~mm}$, the state can be evaluated as full grouting. In the case of greater thickness, this evaluation is doubtful.

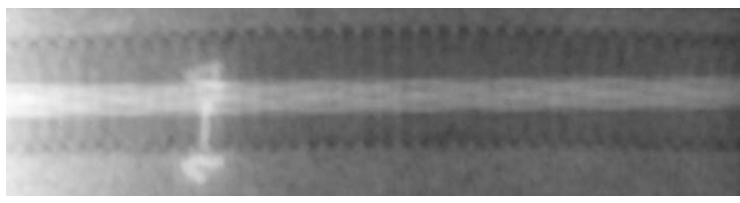

Figure 6: Sample 1, at a thickness of $100 \mathrm{~mm}$, Figure 7: Sample 1, at a thickness of $600 \mathrm{~mm}$,

clearly visible homogeneity of grouting, the picture is not really evaluable.

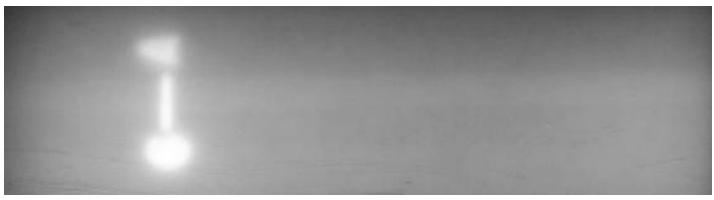




\subsection{Sample 2 - reinforcement grouted to a half of the length of the beam}

On the radiograms, there is a clearly visible characteristic divide between the grouted and the ungrouted part. Differences in the blackening between these parts range from 0.28 (for concrete thickness of $100 \mathrm{~mm}$ ) to 0.12 (for $500 \mathrm{~mm}$ ). Differences disappear only at a thickness of $600 \mathrm{~mm}$, but also here the difference in the centre of the radiogram is apparent.

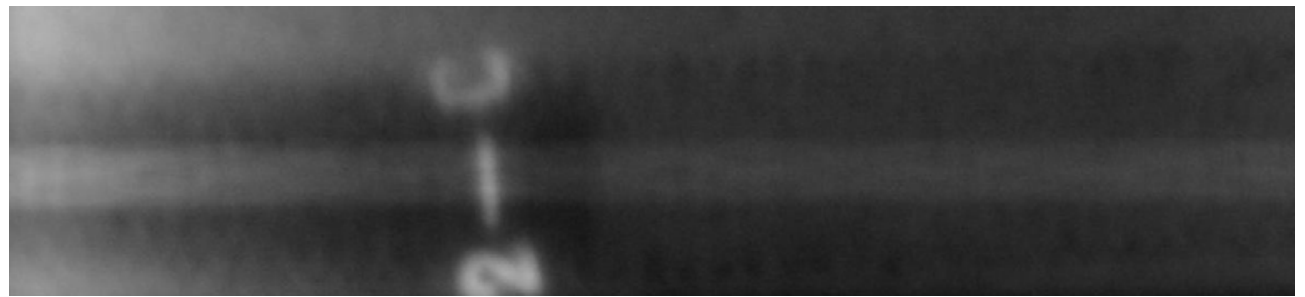

Figure 8: Sample 2, clearly visible difference on the divide between the grouted and the ungrouted part.

\subsection{Sample 3 - reinforcement completely ungrouted}

In the area of the sleeve, radiograms show a distinct blackening in comparison to the area outside the sleeve (at a thickness of $100 \mathrm{~mm}$, the difference in blackening is 0.44 , at $300 \mathrm{~mm}$ it is 0.21 ).

At a concrete thickness above $300 \mathrm{~mm}$, it begins to be difficult to evaluate the edges of the radiogram, where the differences in blackening almost fade away.

At a concrete thickness above $500 \mathrm{~mm}$, it is no longer possible to evaluate the radiogram without having a comparison of its grouted and ungrouted part attached to it.

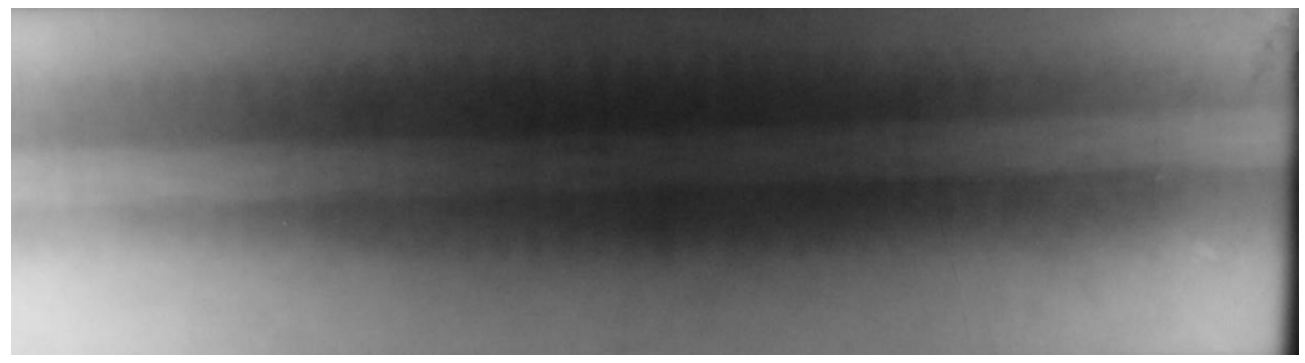

Figure 9: $\quad$ Sample 3, at a thickness of $\mathbf{4 0 0} \mathbf{~ m m}$, the marginal areas of the radiogram are not evaluable.

\subsection{Sample 4 - reinforcement grouted to a half of the height of the beam (perpendicularly)}

The evaluation of radiograms can be described as a combination of the previous cases. Due to great differences in the blackening of the grouted and ungrouted areas, it is possible to identify the grouting defect very well up to a concrete thickness of $600 \mathrm{~mm}$. At thicknesses above $300 \mathrm{~mm}$, it begins to be apparent that the blackening of the radiogram edges is lower and the evaluation of the marginal parts therefore more complicated. 


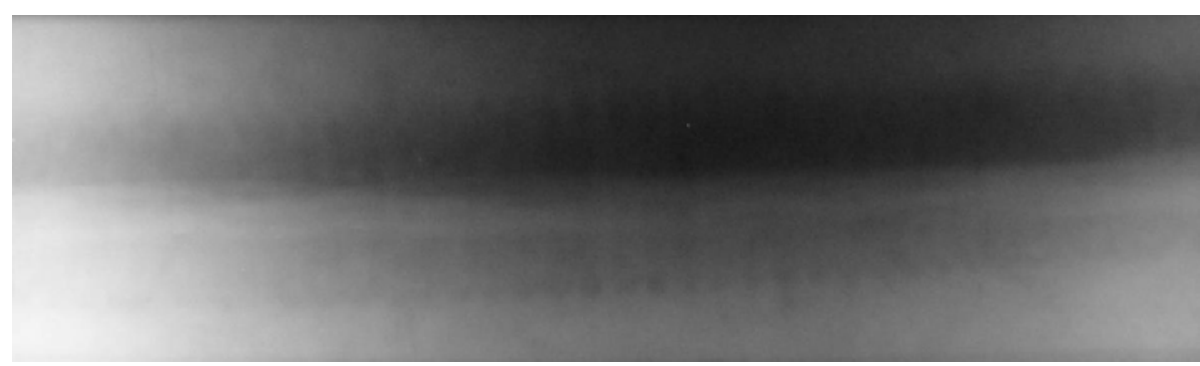

Figure10: Sample 4, at a thickness of $\mathbf{4 0 0} \mathbf{~ m m}$ the marginal areas of the radiogram are not evaluable, but in the centre there is a clearly visible grouting defect.

\subsection{Sample 5 - reinforcement grouted to a half of the height of the beam (diagonally)}

The evaluation of radiograms can be described as a combination of the previous cases in samples 2 and 4. Differences in the blackening are not as distinct as in the previous cases, due to the overlapping of grouted and ungrouted areas (owing to the direction of radiation passage), nevertheless, it is possible to identify very well the ungrouted part of the profile up to a concrete thickness of $600 \mathrm{~mm}$. At thicknesses above $300 \mathrm{~mm}$, it again begins to be apparent that the blackening of the radiogram edges is lower and the evaluation of the marginal parts therefore more complicated.

\section{IDENTIFICATION OF THE HOLES - CONCLUSIONS}

It follows from the experiment that the possibility of hole identification evidently decreases proportionally to the thickness of the concrete, depending on the size of the hole. When Co-60 is used, the dependence between the thickness and the size of a hole of a circular section is given in Fig. 69.

Similarly, the possibility to evaluate the correctness of grouting of the prestressing reinforcement in the examined case depends, not only on the thickness of concrete, but also on the form of the grouting defect and the geometry of irradiation.

In the case of the method used, the thickness of concrete that can be regarded as reliable for the evaluation of radiograms and for determining the correctness of reinforcement grouting is $500 \mathrm{~mm}$. Above this value, the evaluation is not accurate any more, except for the case when a radiogram captures the sharp transition between the grouted and ungrouted part.

At a thickness above $300 \mathrm{~mm}$, the evaluation of the marginal parts of radiograms is not reliable any more, and if there was a defect there, it would be impossible to identify it. In the case of using radiography in situ it is therefore necessary to make several mutually overlapping exposures, so that the marginal area of one exposure is pictured in the centre of the neighbouring one. This will minimize the risk of non-detection of the defect.

\section{REFERENCES}

Anton, O.; Svoboda, D. The posibility of identification of the reinforcement in concrete using by radiographic checking with Co60. In Intrenational Topical Meeting VVER 2007. Praha, UJV. 2007. p. 1 - 6. ISBN 978-80-02-01980-0.

Anton, O.: Radiografická kontrola výztuže pomocí Co60 možnost přesného určení typu výztuže $\mathrm{v}$ závislosti na prozařované tloušt'ce. In Konference Zkoušení a jakost ve stavebnictví 2007. Praha, ČVUT v Praze. 2007. p. 145 - 150. ISBN 978-80-01-03794-2. 